\title{
Characteristics and Mechanism of Salinized Triethanolamine as Cement Grinding Aids
}

\author{
Changsen ZHANG \\ School of Materials Engineering Yancheng Institute of \\ Technology \\ Yancheng, P.R. China \\ E-mail: zcsen1@163.com
}

\author{
Jianli ZHANG \\ School of Materials Engineering Yancheng Institute of \\ Technology \\ School of Materials Science and Engineering \\ Changzhou University \\ Changzhou, P.R. China \\ E-mail: kuaile_zjl@163.com
}

\author{
Zhenzhe FENG \\ School of Materials Science and Engineering \\ Jiangsu University \\ Zhenjiang, P.R. China \\ E-mail: fzzhe1@163.com
}

Baogui ZHU

School of Materials Science and Engineering Jiangsu University

Zhenjiang, P.R. China

E-mail: 18262383300@163.com

\author{
Yang LI \\ School of Materials Science and Engineering \\ Changzhou University \\ Changzhou, P.R. China \\ E-mail: 18262383539@163.com
}

\begin{abstract}
Effects of salinized triethanolamine as cement grinding aids on particles characteristics and mechanical property of cement were studyed, and its reaction mechanism was analyzed by FT-IR, SEM and XRD. According to the results, when the amount of triethanolamine salinization(DGA) was $0.03 \%$, the sieve residue of $45 \mu \mathrm{m}$ was lowered by $47.2 \%$, specific surface area was increased by $45 \mathrm{~m}^{2} / \mathrm{kg}$, the particle size distribution of cement which ranges from 3 to $32 \mu \mathrm{m}$ increased $10.6 \%$. The compressive strength of cement in 3,7 and $28 \mathrm{~d}$ were increased by 4.9, 5.0 and 3.5 MPa, respectively. Enhancement of DGA on cement mainly lied in that it could promote or induce hydration reaction of cement mineral with gypsum and water, which accelerated formation of hydration products, and then improved the structure and morphology of cement hydration products, thus the uniformity and compactness of hydration products structure increased.
\end{abstract}

Keywords-salinized triethanolamine; grinding aids; particles properties; strength; cement

\section{INTRODUCTION}

Cement world production currently increases up to approximately 4 billion tons/year. The electrical energy consumed in cement production is $110 \mathrm{KW} /$ tone and about $30 \%$ of which is used for raw material preparation and about of $40 \%$ for final cement clinker grinding[1-3]. This leads to important cost increase of the final product, especially under the present energy scarce environment[4].

During comminution of clinkers, highly reactive positive and negative charges are created on the newly fractured surfaces. As a result, the agglomeration phenomenon of solid particles occurred due to Van der Waals force and electrostatic attraction, which results in the formation of coatings in the grinding media and reduces the grinding efficiency[5]. In order to improve the energy efficiency of cement production process, one of successful directions is extensive use of grinding aid in comminution process. Because of highly organic polar nature, grinding aid is generally absorbed on particle surface through physical or chemical interaction with cement salts[6]. Due to particle surface state transformation, new charges are neutralized and attractive surface forces are screened, leading to lower grain surface hardness and better dispersion ability of particles.

Although there are a variety of grinding aids in the cement industry, the triethanolamine (TEOA) is extensive used at domestic and overseas. TEOA has a good comprehensive performance that it can improve the effect of grinding, promote the hydration process and enhance the early strength of cement[7-8]. However, TEOA also has limitations and shortcomings that application performance of TEOA is sensitive to its dosage and expensive costing [910]. So, with the development trend of cement industry, it is necessary to modify TEOA to improve performance and lower the cost.

During the study on TEOA modification by organic carboxylic acid, we found incidentally that by proper chemical modification TEOA had excellent grinding performance. The overall goal is to modify TEOA and 
research its effect on grindability and cement performance including standard consistency and compressive strengths. To the best of our knowledge, this is the seldom report about the usage of organic carboxylic acid to salinize TEOA as cement grinding aids. As known, the nitrogen atoms of TEOA structure has the lone pair electrons, so, TEOA has the characteristics of weak alkaline. And then, TEOA can react with organic acid to form a salt improving its performance[11]. Therefore, this paper mainly focused on the grinding performance and effect of DGA on cement properties.

\section{EXPERIMENTAL}

\section{A. Materials}

Triethanolamine, Organic carboxylic acid and sodium hydroxide were all analytical grades, and purchased from Tianjin Chemical Reagent Co. Ltd. (China). Deionized water was used throughout the following work. All other reagents were analytic grade without further purification.

Cement clinker and gypsum was supplied by Jiangsu baling, conch cement Co. Ltd

TABLE I. THE CHEMICALCOMPOSITIONS OF CLINKER AND GYPSUM

\begin{tabular}{cccccccc}
\hline$\%$ & $\mathrm{SiO}_{2}$ & $\mathrm{CaO}$ & $\mathrm{Al}_{2} \mathrm{O}_{3}$ & $\mathrm{Fe}_{2} \mathrm{O}_{3}$ & $\mathrm{MgO}$ & $\mathrm{SO}_{3}$ & LOI \\
\hline Clinker & 21.8 & 65.8 & 5.4 & 3.3 & 1.7 & 0.4 & 0.4 \\
Gypsum & 3.3 & 37.6 & 1.3 & 0.3 & 1.3 & 36.2 & 15.8 \\
\hline
\end{tabular}

(China).The chemical composition of the clinker and gypsum used are reported in Tab. 1.

Triethanolamine modifier (DGA): it was synthesized by TEOA, organic carboxylic acid through specific synthesis process of salinization reaction. And then the reactant is adjusted by sodium hydroxide to neutral. DGA can dissolve with water.

The infrared spectra(IR) of TEOA and DGA are shown in Fig. 1.

\section{B. Methods}

a) Grinding experimental methods:

The cement clinker was crushed by PE60 $\mathrm{mm} \times 100 \mathrm{~mm}$ jaw crusher, and then clinker with the same size was selected.

The selected cement clinker and dihydrate gypsum(the mass ratio of 95:5) were put into a QM-3SP2 planetary ball mill for grinding. The TEOA and DGA were respectively added into planetary ball mill in different dosages: $0.01 \%$, $0.03 \%, 0.05 \%, 0.07 \%, 0.1 \%$ (weight percent of solid content to clinker and gypsum). Grinding time is $20 \mathrm{~min}$.

\section{b) Test methods:}

IR was tested and analyzed by the Fourier transform infrared spectroscopy according to the Chinese National Standard GB/T6040-2002; The testing method for fineness of cement-Sieving method (GB/T1345-2005); The testing method for specific surface area of cement-Blaine method (GB/T8074-2008); The testing method for particle size distribution of cement - Laser method (JC/T721-2006); The testing method of strength for cement mortar-ISO method
(GB/T17671-1999); The morphology, mineral phase and hydration degree of cement paste hydration products in different age were analyzed with scanning electron microscopy and X-ray diffraction, respectively.

\section{RESULTS AND DISCUSSION}

\section{A. FT-IR Analysis}

The FT-IR spectra of TEOA and DGA are shown in Fig.1

It can be seen from Fig. 1 that the stretching vibration band of $-\mathrm{OH}$ at $3355 \mathrm{~cm}^{-1}$ and the stretching vibration band of $-\mathrm{CH}_{3},-\mathrm{CH}_{2}$ - at $2919 \mathrm{~cm}^{-1}$ of DGA were nearly consistent with the stretching vibration of TEOA. At the same time, FT-IR of DGA had the stretching vibration band of C-O nearby at $1076 \mathrm{~cm}^{-1}$, the stretching vibration band of $\mathrm{C}-\mathrm{N}$ at $1031 \mathrm{~cm}^{-1}$ and the deformation vibration band of $-\mathrm{CH}_{3},-$ $\mathrm{CH}_{2^{-}}$at $1405 \mathrm{~cm}^{-1}$. The FT-IR of DGA had the carboxylic acid stretching vibration band of $-\mathrm{C}=\mathrm{O}$ at $1724 \mathrm{~cm}^{-1}$, the stretching vibration band of $\mathrm{N}-\mathrm{H}$ at $3151 \mathrm{~cm}^{-1}$ and the deformation vibration band of $\mathrm{N}-\mathrm{H}$ at $1563 \mathrm{~cm}^{-1}$, while there weren't these stretching vibration bands in FT-IR of TEOA. These changes showed that there were $-\mathrm{C}=\mathrm{O}, \mathrm{N}-\mathrm{H}$ functional groups in the molecular structure of DGA, but not in TEOA.

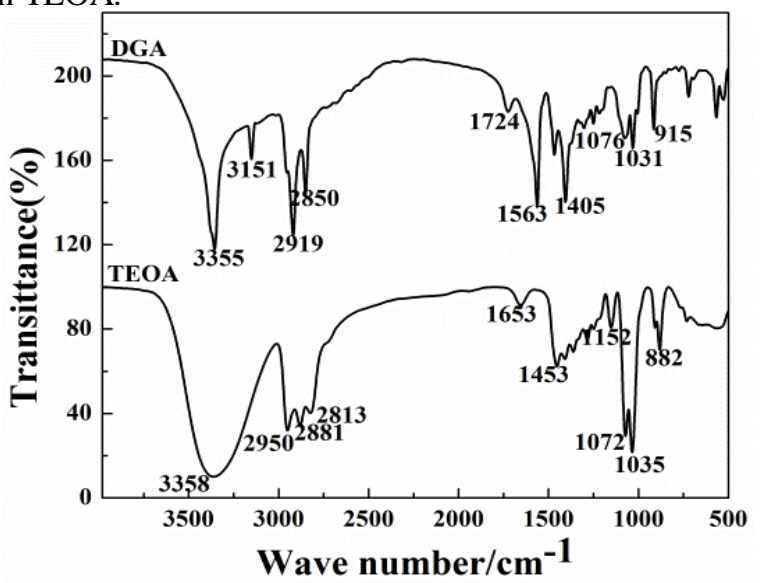

Figure 1. FT-IR spectra of TEOA and DGA

\section{B. Effect of DGA and TEOA on Particles Characteristics of Cement}

Particles characteristics of cement with different dosages of TEOA and DGA are shown in Tab.2. It can be seen from Tab.2 that the fineness of cement with TEOA and DGA are significantly decreased and the specific surface area is apparently increased compared to blank sample. It is shown that TEOA and DGA can significantly reduce the content of coarse particles and increase a few content of fine particles, and the effect of DGA is better than TEOA.

The particle size distribution is the percentage of different diameter particle in all cement particles which is the most important parameter for Portland cement, and directly affects the chemical and mechanical properties of the cement. Researchers have already indicated that the particle of $3 \sim 32 \mu \mathrm{m}$ play a major role in increasing the strength of cement $[12,13]$. 
When the dosage of TEOA and DGA are $0.03 \%$, the specific surface area of TEOA and DGA are separately increased by $31 \mathrm{~m}^{2} / \mathrm{kg}, 45 \mathrm{~m}^{2} / \mathrm{kg}$ and $45 \mu \mathrm{m}$ sieve residue are decreased respectively by $4.1 \%$ and $5.0 \%$.

In all cases the adding of DGA results in higher content of particles $(3 \sim 32 \mu \mathrm{m})$ in comparison with the blank of nonadditive cement. And the effect of DGA on the content of $3 \sim 32 \mu \mathrm{m}$ particles is $5.9 \%$ more than that of blank sample when the dosage of DGA is $0.03 \%$, which also is $1.9 \%$ more than the cement with the same dosage of TEOA.
The results showed that DGA was effective in improvement of cement grindability. After joining the DGA, the cement was introduced the reactive groups. These reactive groups reduced the particle's surface energy, reduced the stress needed for the crack propagation and neutralize the unsaturated electricity of surface, and then improved effective content of particle.

TABLE II. Fineness AND PARTICle Size Distribution of CEMENT with DifFERENT DOSAGES OF TEOA, DGA

\begin{tabular}{|c|c|c|c|c|c|c|c|}
\hline \multirow[b]{2}{*}{ Sample } & \multirow[b]{2}{*}{$\begin{array}{c}\text { Dosage } \\
(\%)\end{array}$} & \multirow{2}{*}{$\begin{array}{l}\text { Specific } \\
\text { surface } \\
\left(\mathrm{m}^{2} / \mathrm{kg}\right)\end{array}$} & \multirow{2}{*}{$\begin{array}{l}45 \mu \mathrm{m} \\
\text { sieve } \\
\text { residue } \\
(\%)\end{array}$} & \multicolumn{4}{|c|}{ Particle size distribution $(\%)$} \\
\hline & & & & $\leq 3 \mu \mathrm{m}$ & $3-32 \mu \mathrm{m}$ & $32-60 \mu \mathrm{m}$ & $\geq 60 \mu \mathrm{m}$ \\
\hline Blank & 0 & 340 & 10.6 & 7.9 & 55.4 & 23.9 & 12.8 \\
\hline \multirow{2}{*}{ TEOA } & 0.03 & 371 & 6.5 & 10.8 & 59.4 & 22.4 & 8.4 \\
\hline & 0.05 & 369 & 7.1 & 10.5 & 58.9 & 22.1 & 8.5 \\
\hline \multirow{2}{*}{ DGA } & 0.03 & 385 & 5.6 & 11.4 & 61.3 & 21.8 & 5.5 \\
\hline & 0.05 & 382 & 6.0 & 11.3 & 61.0 & 21.6 & 6.1 \\
\hline
\end{tabular}
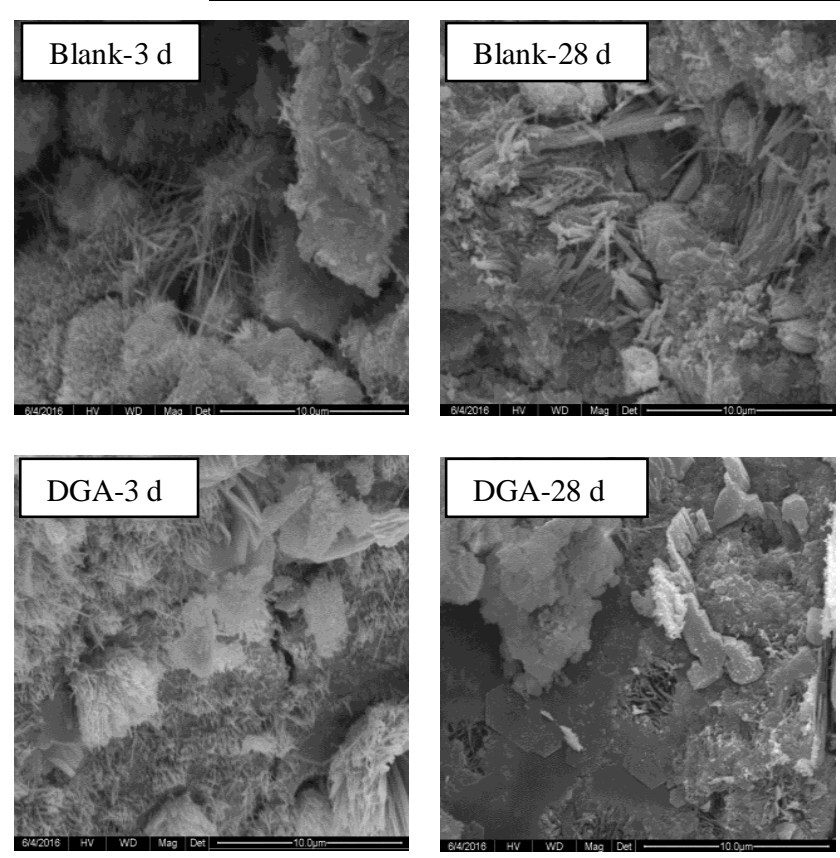

Figure 2. SEM images of hydration product of cement paste at $3 \mathrm{~d}$ and $28 \mathrm{~d}$

\section{Effect of DGA and TEOA on Physical Mechanical Performance of Cement}

Physical and mechanical properties of cement with different types and dosages of grinding aids are shown in Tab. 3 .

It can be seen from Tab. 3 that soundness of all cement are eligible, the compressive strength of cement with DGA at 3, 7 and $28 \mathrm{~d}$ are improved significantly. And the effect is the best when the dosage of DGA is $0.03 \%$. The compressive strengths of cement at 3,7 and $28 \mathrm{~d}$ are respectively increased by $4.9,5$ and $3.5 \mathrm{MPa}$. When the dosage of DGA is $0.03 \%$ (it is $1.8,1.6$ and $4.3 \mathrm{MPa}$ respectively higher than TEOA at the same dosage). On one hand, the enhancement effect is directly related the content of $3 \sim 32 \mu \mathrm{m}$ particles of cement which is improved significantly by adding DGA. On the other hand, the carboxyl of the grinding aids reacted with $\mathrm{Ca}^{2+}$ in cement, which could accelerate the hydration process of $\mathrm{C}_{3} \mathrm{~S}$, produce insoluble calcium salt and improve the strength and density of hydration product. The complexation of carboxyl groups promoted the hydrolysis of $\mathrm{C}_{3} \mathrm{~A}$ in the early stage of cement reaction, forming the gelatinous $\mathrm{AFt}$, and then improved the early strength of cement.

TABLE III. PHYSICAL AND MECHANICAL PROPERTIES OF CEMENT WITH DIFFERENT TYPES AND DOSAGES OF GRINDING AIDS

\begin{tabular}{cccccc}
\hline \multirow{2}{*}{ Sample } & \multirow{2}{*}{$\begin{array}{c}\text { Dosage } \\
(\%)\end{array}$} & Soundess & \multicolumn{3}{c}{$\begin{array}{c}\text { Compressive } \\
\text { strength(MPa) }\end{array}$} \\
\cline { 4 - 6 } & & & $3 \mathrm{~d}$ & $7 \mathrm{~d}$ & $28 \mathrm{~d}$ \\
\hline Blank & 0 & Eligible & 31.2 & 38.5 & 50.3 \\
TEOA & 0.03 & Eligible & 34.3 & 41.9 & 49.5 \\
& 0.05 & Eligible & 32.5 & 40.8 & 49.5 \\
DGA & 0.03 & Eligible & 36.1 & 43.5 & 53.8 \\
& 0.05 & Eligible & 35.6 & 43.0 & 53.4 \\
\hline
\end{tabular}

D. SEM Analysis of Cement Hydration Products

The cement paste micro test was carried out with DGA at the dosage of $0.03 \%$.

SEM of hydration products for cement paste at 3 and 28 d are shown in Fig. 2.

It can be seen from Fig. 2 that hydration product structure of blank cement at $3 \mathrm{~d}$ is relatively loose and has more pores. It contains a large amount of cement clinker minerals that it hasn't occurred hydration reaction. A small amount of layered $\mathrm{Ca}(\mathrm{OH})_{2}$ is fuzzy visible and Amorphous $\mathrm{C}-\mathrm{S}-\mathrm{H}$ gel is seldom distributed in hydration structure. However, hydration product structure of cement with DGA at $3 \mathrm{~d}$ is relatively dense, its structure has a little number of cement clinker minerals that it hasn't occurred hydration reaction. C-S-H and $\mathrm{Ca}(\mathrm{OH})_{2}$ in hydration structure overlap with each other form a more stable micro-structure. 
It can be seen from Fig. 2 that hydration product structure of blank cement at $28 \mathrm{~d}$ is have a large number of gelatinous $\mathrm{AFt}$, the morphology of which has been unable to identify and the structure is relatively dense. The hydration of cement paste with DGA is more thoroughly and paste structure is filled fully with hydration product. A large amount of layered $\mathrm{Ca}(\mathrm{OH})_{2}$ is fuzzy visible. The pore of the cement stone is very few, is formed integrally, and then the structure of hydration product is firm.

In any case, the improved microstructure by addition of DGA resulted in the better strength development, and it promoted reaction process of cement hydration, improved hydration degree of cement, and then more hydration products were produced in the hydration process of cement.

\section{E. XRD Analysis of Cement Hydration Products}

XRD of hydration products for harden cement paste at 3 and $28 \mathrm{~d}$ are shown in Fig. 3 and Fig. 4, respectively.

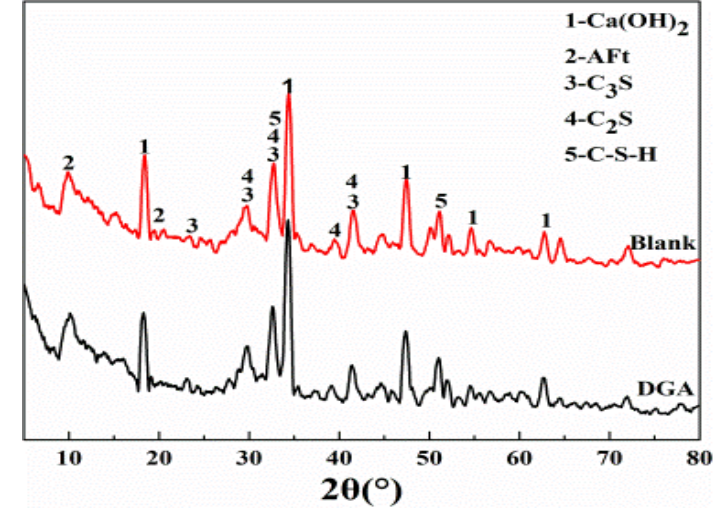

Figure 3. XRD of hydration product for cement paste at $3 \mathrm{~d}$

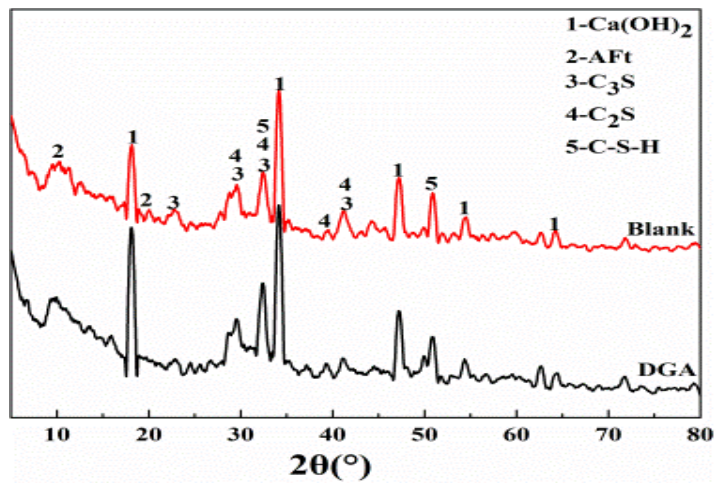

Figure 4. XRD of hydration product for cement paste at $28 \mathrm{~d}$

It can be seen from Fig. 3 and Fig. 4 that the main hydration products are $\mathrm{Ca}(\mathrm{OH})_{2}, \mathrm{AFt}$ and C-S-H. Compared with the blank group, the diffraction peaks of $\mathrm{Ca}(\mathrm{OH})_{2}, \mathrm{AFt}$ and C-S-H in hydration products of cement with DGA at 3 and $28 \mathrm{~d}$ are stronger. This is due to hydration speed of cement with DGA is faster, and more hydration products such as $\mathrm{Ca}(\mathrm{OH})_{2}$ is produced. However the diffraction peaks of $\mathrm{C}_{3} \mathrm{~S}, \mathrm{C}_{2} \mathrm{~S}$ are weak, indicating that $\mathrm{C}_{3} \mathrm{~S}$ and $\mathrm{C}_{2} \mathrm{~S}$ are more involved in the hydration reaction.

The addition of DGA improved the strength of cement paste at different ages. On one hand, the addition of DGA reduced the surface energy of cement particles and improved the effective particle size distribution.

On the other hand, DGA could react with $\mathrm{Ca}^{2+}$ accelerating the hydration reaction rate, and then produced more hydration products, which is beneficial to the development of later strength.

So it indicates that DGA can promotes hydration reaction of clinker, thus strength of cement is improved.

\section{CONCLUSIONS}

- The optimization effect of DGA particles size distribution of cement was better than TEOA. The specific surface area of cement with $0.03 \%$ DGA was $14 \mathrm{~m}^{2} / \mathrm{kg}$ more than that with TEOA at the same dosage. The content of $3 \sim 32 \mu \mathrm{m}$ particles of cement with $0.03 \%$ DGA was $1.9 \%$ higher than that with TEOA at the same dosage.

- DGA could improve significantly mechanical property of cement. The compressively strength of cement with $0.03 \%$ DGA at 3,7 and $28 \mathrm{~d}$ was increased by 1.8, 1.6 and $4.3 \mathrm{MPa}$, respectively.

- DGA had the amino, hydroxyl and carboxyl groups, which easily combined with metalions of cement particles, resulting in that DGA could promote surface adsorption and shield the unsaturated charges in the surface and crack section of particles, and then particles reunion was prevented. Thus DGA exhibited an excellent dispersing and grinding effect.

\section{ACKNOWLEDGEMENT}

This work was supported by the Research for National Natural Science Foundation of China (No. 51672236).

\section{REFERENCES}

[1] Jankovic Alex, Valery Walter, Davis Eugene. Cement grinding optimization. Miner Eng 2004; 17:1075-81.

[2] Dundar H, Benzer H, Aydogan NA, Altun O, et al. Simulation assisted capacity improvement of cement grinding circuit: case study cement plant. Miner Eng 2011; 24; 205-10.

[3] Benzer H, Ergun L, Oner M, Lynch AJ. Simulation of open circuit clinker grinding. Miner Eng 2001; 14(7): 01-10.

[4] [4] Atesok G, Ozer M, Boylu F, DVncer H. The effect of anionic dispersants on grindability of different rank coals. Int J Miner Process 2005; 77: 199-207.

[5] Sottili L, Padovani D. Einfluss von Mahlhilfsmitteln in der Zementindustrie. ZKG Int 2000; 53(10): 568-75.

[6] Jeknavorian AA, Barry EF, Serafin F. Determination of grinding aid in Portland cement by pyrolysis PGAs chromatography-mass spectrometry. Cem Concr Res 1998; 28(9):1335-1345.

[7] X Kong, LU Zhenbao, Y Zhang, Z Zhang,Y Jin. Effect of Organic Grinding Aids on Cement Properties and the Analysis via Organic Cement Chemistry[J] J. Chin. Ceram. Soc., 2012, 40(1): 49-55.

[8] X Zhu, H Hou, X Huang, M Zhou, W Wang. Enhance Hydration Properties of Steel Slag Using Grinding Aids by Mechanochemical Effect[J]. Constr. Build. Maters, 2012, 29(4): 476-481.

[9] Ma B G, Xu Y H, Dong R Z. Influence of Triethanolamine on the Initial Structure Formation and Mechanical Properties of Cement[J]. J. Build. Mater., 2006 , 9(1):6-9. 
[10] Li X J. Effect of Grinding Aids on Adsorption Quantity of Superplasticizer on the Surface of Cement Particles[J]. Concr., 2010(6):71-73.

[11] J Han, K Wang, J Shi, Y Wang. Mechanism of triethanolamine on Portland cement hydration process and microstructure characteristics[J]. Construction Building Materials, 2015,93:457-462.
[12] M Katsioti, PE Tsakiridis, P Giannatos, Z Tsibouki, J Marinos. Characterization of various cement grinding aids and their impact on grindability and cement performance. Constr Build Mater, 2009, 23(5):1954-1959.

[13] I Teoreanu, G Guslicov. Mechanisms and effects of additives from the dihydroxy-compoundclass on Portland cement grinding. Cem Concr Res, 1999, 29(1):9-15. 